\title{
Development of an Optimized Converter Layer for a Silicon-Carbide-Based Neutron Sensor for the Detection of Fissionable Materials
}

\author{
Stephen D. Monk, Simon P. Platt, Member, IEEE, Michael J. Anderson, Mustafa Alhamdi, and David Cheneler
}

\begin{abstract}
We describe the early stage development of a miniature silicon carbide neutron sensor, for applications including robotic monitoring at the Fukushima Daiichi nuclear power plant, specifically, within the primary containment vessel for fuel debris detection and retrieval. Monte Carlo simulations using MCNP 6.2 and Geant4 10.05.01 are used to investigate and optimize converter layers for thermal neutron detection. Performance of a ${ }^{10} \mathrm{~B}_{4} \mathrm{C}: \mathrm{SiC}$ detector system is investigated in detail and a neutron detection efficiency $\sim 4 \%$ is predicted, with a gamma discrimination ratio of the order of $10^{5}$.
\end{abstract}

Index Terms-Fukushima Daiichi Nuclear Power Plant, Radiation monitoring, Neutrons, Semiconductor radiation detectors, Silicon carbide, Monte Carlo methods

\section{INTRODUCTION}

$\mathbf{F}$ OLLOWING the Great East Japan earthquake of 2011, fuel, fissile material, activated isotopes and structural materials were distributed in the bottom of the Primary Containment Vessel (PCV) and housing areas within the Fukushima Daiichi Nuclear Power Plant (NPP). This presented both a hazard to the restoration teams and also a challenge in the longer term decommissioning and dismantling procedures. Specific problems in this environment include the presence of an unknown mixture of fuel and activated waste emitting a variety of radiation types, an environment of extremes in temperature or humidity, high gamma background radiation (estimated to be up to $1000 \mathrm{~Gy} \mathrm{~h}^{-1}$ ), limited access in terms of physical size and weight for tools to aid remedial work, and limited access in terms of time due to worker dose limits.

In order to function within this harsh environment, instrumentation and electronics need to be radiation hardened. Operations within the plant require a sensor system capable of detecting both fast and thermal neutrons with low sensitivity to gamma radiation and which can operate at elevated temperature and high humidity. The device must be small, for robotic deployment in constrained areas including cracks and gaps. Development of a thin neutron detector system, using silicon carbide for the detector and front end electronics, is in progress

\footnotetext{
This work is supported by the UK Engineering and Physical Sciences Research Council, grant reference EP/S020411/1, and is part of the UK Japan Civil Nuclear Research Programme.

S. D. Monk, S. P. Platt and D. Cheneler are with the Engineering Department, Lancaster University, Lancaster, LA1 4YW. Email: s.monk@lancaster.ac.uk

M. J. Anderson is with with the Engineering Department, Lancaster University, and Innovative Physics Ltd., Landguard Manor, Landguard Manor Road, Shanklin, Isle of Wight, PO37 7JB.

M. Alhamdi is with Innovative Physics Ltd.
}

TABLE I: Thin neutron detector system key requirements

\begin{tabular}{lccc}
\hline & nominal & $\begin{array}{c}\text { localised } \\
\text { worst case }\end{array}$ \\
\hline neutron fluence rate $/ \mathrm{cm}^{-2} \mathrm{~s}^{-1}$ & & $10^{7}$ & $10^{13}$ \\
gamma dose rate $/ \mathrm{Gy} \mathrm{h}^{-1}$ & 0.1 & 1000 \\
temperature $/{ }^{\circ} \mathrm{C}$ & $>60$ & & \\
humidity & condensing/submerged & \\
thickness $/ \mathrm{mm}$ & $<3$ & & \\
\hline
\end{tabular}

with the aim of achieving an integrated system with a final thickness below $3 \mathrm{~mm}$. Key requirements for the thin neutron detector system front-end are listed in Table I.

Silicon carbide is a promising semiconductor material for use in high-temperature and high-radiation environments, [1][3] and is increasingly being used both for radiation detection [4]-[15] and for integrated electronics [16], [17].

Fast neutron detection in a semiconductor device can be achieved by detecting charged particles resulting from interactions with the semiconductor material itself (silicon or carbon nuclei, in the case of $\mathrm{SiC}$ ). Thermal neutron detection requires the sensor to incorporate a suitable converter material to generate energetic charged particles from neutron capture reactions. Such converters can be based on lithium, boron or gadolinium, all of which have exothermic neutron capture reactions. In the present work, we focus on the analysis and optimization of a suitable converter layer for our application, by undertaking Monte Carlo simulations with MCNP [18]. We consider choice of converter material, its thickness, and its isotopic enrichment. We also consider the influence of detector geometry and its gamma rejection. The results of preliminary simulations using Geant4 [19]-[22] are also presented.

\section{Detector CONFIGURATION}

The detector under consideration here is a simple mesa PN junction diode with converter layer. The configuration is shown schematically in Fig. 1.

The diode active region is formed by a lightly-doped n-type $\mathrm{SiC}$ epitaxial layer on a highly-doped $\mathrm{n}$-type $\mathrm{SiC}$ substrate. A highly-doped p-type region forms a PN junction with the active region. Anode and cathode contacts are made to the $\mathrm{p}^{+}$and $\mathrm{n}^{+}$ regions, respectively. A converter layer is deposited on the $\mathrm{p}^{+}$ surface. The diode is operated in reverse bias, such that the depletion region extends throughout the $\mathrm{n}^{-}$region. Electron-hole pairs generated in the depletion region by energetic charged 


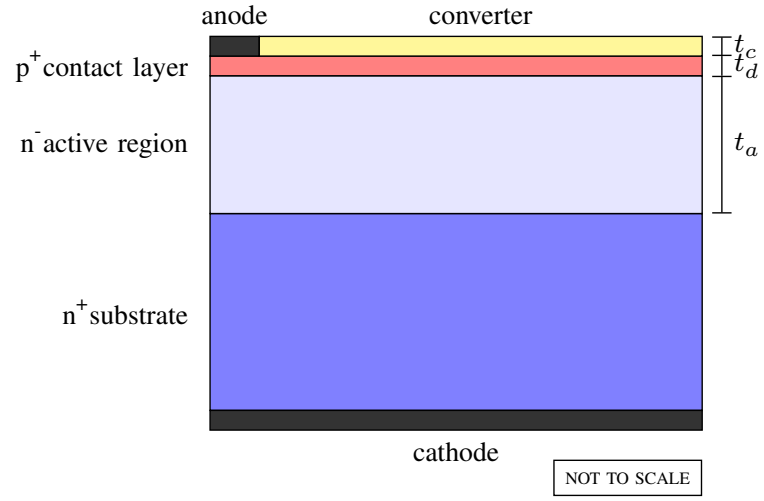

Fig. 1: Detector schematic. $t_{c}, t_{d}$, and $t_{a}$ are the thicknesses of the converter, contact ("dead") and active layers, respectively.

TABLE II: Selected material parameters of $4 \mathrm{H}-\mathrm{SiC}$ and $\mathrm{Si}$

\begin{tabular}{lllc}
\hline & & $\mathrm{SiC}$ & $\mathrm{Si}$ \\
\hline band gap & $\mathrm{eV}$ & 3.27 & 1.12 \\
ionization energy & $\mathrm{eV}$ & 7.78 & 3.6 \\
relative permittivity & & 9.7 & 11.9 \\
density & $/ \mathrm{g} \mathrm{cm}^{-2}$ & 3.2 & 2.3 \\
\hline
\end{tabular}

particles lead to a detectable electronic signal. The charged particles themselves can be generated either by interactions of high-energy neutrons in or close to the active region, for example silicon or carbon recoils from elastic scattering, or else by the interactions of low-energy neutrons with the converter material.

We consider diodes with active region depth in the range from $5 \mu \mathrm{m}$ to $20 \mu \mathrm{m}$ and active area $\sim 1 \mathrm{~cm}^{2}$. A SiC PN diode with area $\sim 1 \mathrm{~cm}^{2}$ and depletion depth $\sim 10 \mu \mathrm{m}$ has capacitance $\sim 1 \mathrm{nF}$. At temperatures in the range from $20^{\circ} \mathrm{C}$ to $60^{\circ} \mathrm{C}$ the thermal noise in such a device is $\sim 2 \mathrm{fC}_{\text {r.m.s. }}$. Taking the lower limit of detection to be at least $3 \times$ r.m.s. noise level, $\sim 6 \mathrm{fC}$, results in a minimum detectable energy deposited in the active region $\sim 0.3 \mathrm{MeV}$.

\section{CHOICE OF CONVERTER LAYER MATERIAL}

Converter layers used to detect thermal neutrons with semiconductor detectors are usually based on lithium, boron, or, sometimes, gadolinium. Table III lists the well known neutron conversion characteristics for the most important isotopes of these elements. Cross-sections are given at $25.3 \mathrm{meV}$, the most likely thermal neutron energy at $20^{\circ} \mathrm{C}$, and are taken from the latest ENDF/B-VIII.0 database [23], [24].

${ }^{6} \mathrm{Li}$ (or compounds, such as ${ }^{6} \mathrm{LiF}$ ) and ${ }^{10} \mathrm{~B}$ (or compounds, such as ${ }^{10} \mathrm{~B}_{4} \mathrm{C}$ ) have been widely used as thermal neutron converter materials in semiconductor and gaseous detectors [25][32]. Neutron capture by ${ }^{6} \mathrm{Li}$ emits two energetic charged particles, a triton and alpha particle, either one of which might enter the active region and be detected. Similarly, neutron capture by ${ }^{10} \mathrm{~B}$ emits an alpha particle and a lithium ion. By comparison with ${ }^{6} \mathrm{Li},{ }^{10} \mathrm{~B}$ emits reaction products with somewhat less kinetic energy but with substantially greater cross-section.
TABLE III: Key neutron conversion characteristics

\begin{tabular}{|c|c|c|c|c|}
\hline isotope & reaction & $\begin{array}{c}\text { cross-section } \\
/ \mathrm{b}\end{array}$ & product & $\begin{array}{l}\text { energy } \\
/ \mathrm{MeV}\end{array}$ \\
\hline \multirow{2}{*}{${ }^{6} \mathrm{Li}$} & \multirow{2}{*}{${ }^{6} \mathrm{Li}(\mathrm{n}, \mathrm{t}){ }^{4} \mathrm{He}$} & \multirow{2}{*}{938} & ${ }^{3} \mathrm{H}^{1+}$ & 2.73 \\
\hline & & & $\alpha$ & 2.06 \\
\hline \multirow{4}{*}{${ }^{10} \mathrm{~B}$} & \multirow{2}{*}{${ }^{10} \mathrm{~B}(\mathrm{n}, \alpha){ }^{7 \mathrm{~m}} \mathrm{Li}$} & \multirow{2}{*}{3602} & $\alpha$ & 1.47 \\
\hline & & & $\mathrm{Li}^{3+}$ & 0.84 \\
\hline & \multirow{2}{*}{${ }^{10} \mathrm{~B}(\mathrm{n}, \alpha)^{7} \mathrm{Li}$} & \multirow{2}{*}{242} & $\alpha$ & 1.78 \\
\hline & & & ${ }^{7} \mathrm{Li}^{3+}$ & 1.01 \\
\hline \multirow{3}{*}{${ }^{157} \mathrm{Gd}$} & \multirow{3}{*}{${ }^{157} \mathrm{Gd}(\mathrm{n}, \gamma){ }^{158} \mathrm{Gd}$} & \multirow{3}{*}{252928} & \multirow{3}{*}{$\mathrm{e}^{-}$} & 0.029 \\
\hline & & & & 0.071 \\
\hline & & & & 0.078 \\
\hline \multirow{3}{*}{${ }^{155} \mathrm{Gd}$} & \multirow{3}{*}{${ }^{155} \mathrm{Gd}(\mathrm{n}, \gamma){ }^{156} \mathrm{Gd}$} & \multirow{3}{*}{60740} & \multirow{3}{*}{$\mathrm{e}^{-}$} & 0.039 \\
\hline & & & & 0.081 \\
\hline & & & & 0.088 \\
\hline
\end{tabular}

Gadolinium has a still larger cross-section for neutron capture, and has also been used as a converter layer on semiconductor detectors. [33]-[36] Several gadolinium isotopes have very high cross-sections, most notably ${ }^{155} \mathrm{Gd}$ and, especially, ${ }^{157} \mathrm{Gd}$, which form $\sim 15 \%$ and $\sim 16 \%$, respectively, of natural gadolinium. Neutron capture in gadolinium does not lead to emission of ionizing nuclear particles; however, internal conversion leads to the emission of electrons at several discrete energies, the most prominent of which are listed in Table III. Kandlakunta et al. [33], [34] have shown that the electron spectrum arising from neutron capture in natural gadolinium is dominated by a peak at $71 \mathrm{keV}$.

The ionizing energy of the reaction products from neutron capture by ${ }^{10} \mathrm{~B}$ and ${ }^{6} \mathrm{Li}$ are sufficient to be detected at the likely detection threshold $(300 \mathrm{keV})$. The electrons resulting from neutron capture by gadolinium do not exceed the likely minimum detectable energy, and gadolinium is therefore excluded from our choice of converter layer. It is significant that the successful use of gadolinium as a neutron converter [34], [35] has been with silicon detectors (pulse heights $\sim 2 \times$ those in $\mathrm{SiC}$ ) with thick active regions (encompassing the longer range of lighter reaction products and resulting in lower capacitance and lower detection thresholds, e.g. $\sim 20 \mathrm{keV}$ ).

McGregor et al. [25] investigated ${ }^{10} \mathrm{~B}$ and ${ }^{6} \mathrm{LiF}$ converter layers of the kind considered here and demonstrated that the maximum available thermal neutron detection efficiencies were $\sim 4 \%$ for ${ }^{10} \mathrm{~B}$ converter layers of $\sim 2.4 \mu \mathrm{m}$ thickness and only slightly higher $(\sim 4.4 \%)$ for much thicker ${ }^{6} \mathrm{LiF}$ converter layers $(\sim 27 \mu \mathrm{m})$. We focus our work, therefore, on ${ }^{10} \mathrm{~B}$ converter layers, including isotopically enriched $\mathrm{B}_{4} \mathrm{C}$ [27], [32].

\section{Monte Carlo simulations of neutron Response}

MCNP 6.2 [18] simulations were undertaken for the device configuration of Fig. 1, with active layer thickness from $5 \mu \mathrm{m}$ to $20 \mu \mathrm{m}$, dead zone thickness from $0 \mu \mathrm{m}$ to $0.5 \mu \mathrm{m}$, and ${ }^{10} \mathrm{~B}$ and ${ }^{10} \mathrm{~B}_{4} \mathrm{C}$ converter layers with thicknesses in the range from $1 \mu \mathrm{m}$ to $5 \mu \mathrm{m}$. Detection efficiency is directly proportional to 
the concentration of ${ }^{10} \mathrm{~B}$. In the results shown here a ${ }^{10} \mathrm{~B}$ concentration of $100 \%$ is assumed; ${ }^{10} \mathrm{~B}$ enrichment greater than $90 \%$ has been reported in ${ }^{10} \mathrm{~B}_{4} \mathrm{C}$ converter layers [29]. Detection efficiency is independent of active region depth in the range studied, as the reaction product with the longest range $(1.78 \mathrm{MeV} \alpha)$ travels less than $5 \mu \mathrm{m}$ in silicon carbide $(\sim 4 \mu \mathrm{m})$.

The simulations had the following key characteristics. $25 \mathrm{meV}$ neutrons (monoenergetic) impinged on the upper surface either normally or as a diffuse (Lambertian) source. MCNP "F8" tallies were used to determine energy deposited in the active region by electrons and photons, alpha particles, and heavy ions, and all particle types combined. Validity of the tallies was ensured by invoking self-consistent elastic scattering and the Neutron Capture Ion Algorithm (NCIA) by setting the value of the neutron physics coilf parameter to 4 . The relevant physics cards in the MCNP input deck were as follows:

MODE N P E A \#

CUT:A, \# J 0

CUT: $N, P, E 2 \mathrm{~J} 00$

PHYS:N $100 \quad 100 \quad 4 \mathrm{~J} 4$

PHYS :P $3 \mathrm{~J}-1$

Pulses were tallied in $25 \mathrm{keV}$ bins and simulations were terminated when the statistical precision in the bin from $975 \mathrm{keV}$ to $1000 \mathrm{keV}$ had reached a standard uncertainty below $1 \%$.

Fig. 2 shows the simulated response to normally incident thermal neutrons of a detector with a $2 \mu \mathrm{m}$ converter layer and no dead zone. Although unrealistic, the initial assumption of a negligible dead zone allows simulation results to be compared directly with analytic calculations [25]. The pulse height spectrum in Fig. 2a is normalized to the number of incident neutrons and to the bin width. The edges at $1.47 \mathrm{MeV}$ and $0.84 \mathrm{MeV}$ are due to the alpha particle and lithium ion, respectively, from the dominant $(94 \%)$ branch of the ${ }^{10} \mathrm{~B}(\mathrm{n}, \alpha)$ reaction. The contribution of the alpha particle from the $6 \%$ branch is also visible, at $1.78 \mathrm{MeV}$. The contribution of the corresponding lithium ion, at $1.01 \mathrm{MeV}$, is masked by that of the dominant alpha particle.

The reverse integral of the pulse height spectrum provides a measure of the intrinsic efficiency of the detector versus lower limit of detection, as shown in Fig. 2b. The efficiency of a detector with ${ }^{10} \mathrm{~B}_{4} \mathrm{C}$ is $\sim 80 \%$ of that with a layer of pure ${ }^{10} \mathrm{~B}$, as shown by Fig. 3 for converter thicknesses in the range from $1 \mu \mathrm{m}$ to $4 \mu \mathrm{m}$, consistent with the composition of $\mathrm{B}_{4} \mathrm{C}$.

Fig. 3 shows how the optimum converter thickness for this system is $\sim 2.5 \mu \mathrm{m}$, in agreement with [25]. The efficiency calculated in this work is slightly higher, however, at $4.7 \%$ (cf. $\sim 4 \%$ in [25]).

Fig. 4 shows the response of a more realistic detector, with a $0.5 \mu \mathrm{m}$ dead zone between converter and active layer. The effect of the dead zone is to reduce the energy available for ionization in the active layer. As shown by Fig. 5a, the $1.47 \mathrm{MeV}$ edge in the pulse-height spectrum is shifted to $\sim 1.3 \mathrm{MeV}$, as a $1.47 \mathrm{MeV}$ alpha particle has stopping power $\sim 0.4 \mathrm{MeV}_{\mu \mathrm{m}^{-1}}$ in $\mathrm{SiC}$. Efficiency in this case is reduced by about a factor of 2 (Fig. 5b): although most of the alpha particles are able to penetrate the dead zone, only a very small proportion of the

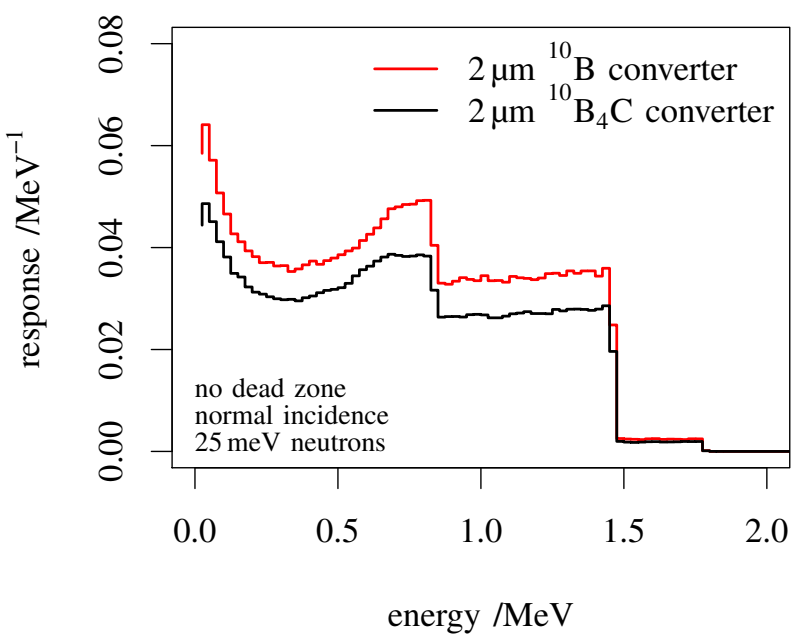

(a) Pulse height spectrum

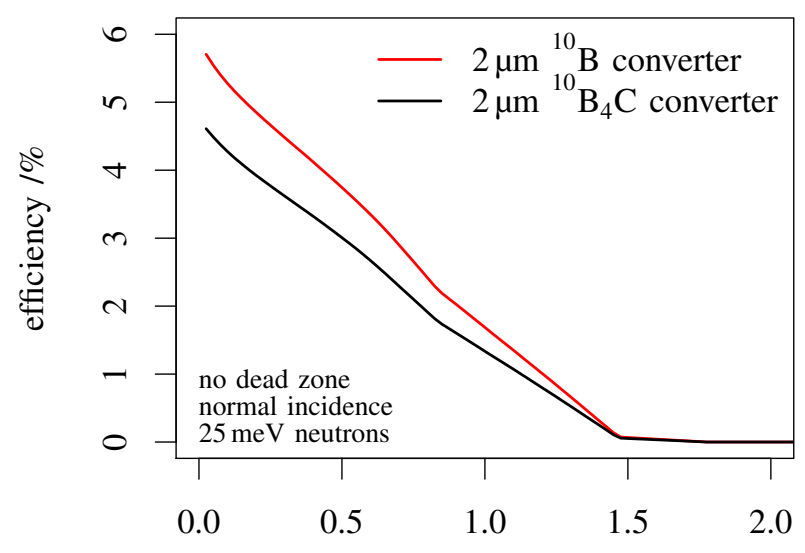

lower limit of detection $/ \mathrm{MeV}$

(b) Intrinsic efficiency

Fig. 2: Neutron response with ${ }^{10} \mathrm{~B}$ and ${ }^{10} \mathrm{~B}_{4} \mathrm{C}$ converters

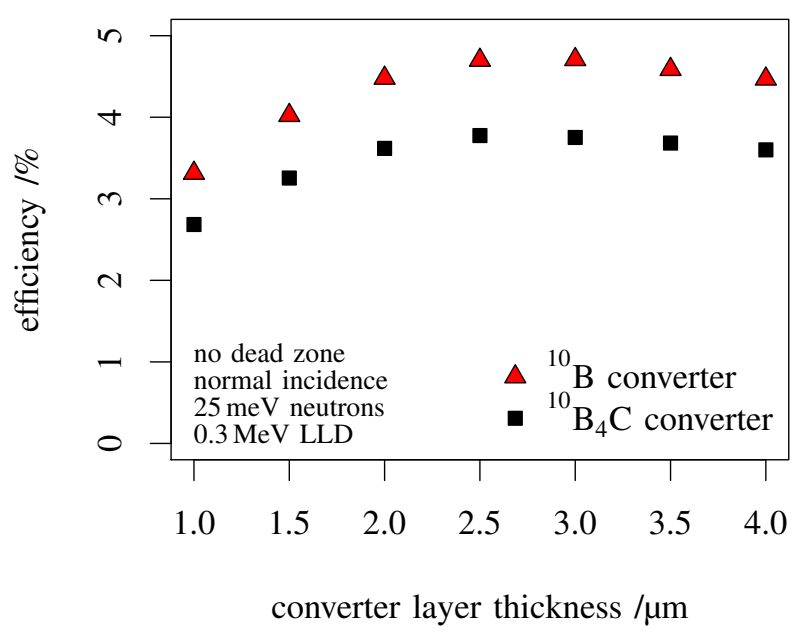

Fig. 3: Intrinsic neutron detection efficiency, $0.3 \mathrm{MeV}$ lower limit of detection 
lithium ions are able to do so with sufficient energy to exceed the lower limit of detection. Almost half the reaction products are thereby lost.

The assumption that all neutrons are incident normally on the front face of the detector is a worst case, and in many applications is unrealistic. Results of simulations showing the effect of a Lambertian neutron source at the upper surface are shown in Fig. 6. The pulse height spectra are qualitatively the same as for normally incident neutrons, but the efficiency is increased by almost a factor of 2 . This is because neutrons arriving off normal have on average a longer path through the converter layer and an increased probability of capture by a ${ }^{10} \mathrm{~B}$ nucleus. The maximum efficiency, at $\sim 2 \mu \mathrm{m}{ }^{10} \mathrm{~B}_{4} \mathrm{C}$ converter thickness, approaches $4 \%$ for ${ }^{10} \mathrm{~B}$ enrichment approaching $100 \%$.

\section{GAMMA REJECTION}

Gamma rejection was investigated by simulating energy deposition from gamma photons at $1.33 \mathrm{MeV}, 1.17 \mathrm{MeV}$, and $662 \mathrm{keV}$, representing emissions from ${ }^{60} \mathrm{Co}$ and ${ }^{137} \mathrm{Cs}$. As the active layer is thin $(\leq 20 \mu \mathrm{m})$ we expect little response from normally incident photons, but the high aspect ratio $(\sim 1000: 1)$ suggests that this response should be highly anisotropic. Fig. 7 shows the simulated response to photons incident at $0^{\circ}$ and $90^{\circ}$ to normal. This is for a detector with $1 \mathrm{~cm} \times 1 \mathrm{~cm}$ surface area and active layer thickness $13 \mu \mathrm{m}$. The response is normalized to photon fluence, to ensure comparability of the two cases.

Fig. 7 shows that very few photons deposit energy above a $0.3 \mathrm{MeV}$ lower limit of detection, even in the worst case studied here $\left(\gtrsim 1 \mathrm{MeV}, 90^{\circ}\right)$, for which the response integrated above $0.3 \mathrm{MeV}$ is $1.6 \times 10^{-6} \mathrm{~cm}^{2}, 4$ orders of magnitude below the comparable response to $25 \mathrm{meV}$ neutrons. We expect the main source of gamma radiation in our application to be ${ }^{137} \mathrm{Cs}$; the corresponding response in that case being $9 \times 10^{-8} \mathrm{~cm}^{2}, 5$ orders of magnitude below the neutron response.

Approximating gamma dose by its corresponding kerma, and taking the air kerma rate constant for ${ }^{137} \mathrm{Cs}$ to be $22.8 \mathrm{aGy} \mathrm{m}^{2} \mathrm{~Bq}^{-1} \mathrm{~s}^{-1}$ [37], the ${ }^{137} \mathrm{Cs}$ photon fluence is $\sim 3 \times 10^{15} \mathrm{~cm}^{-2} \mathrm{~Gy}^{-1}$. For an expected dose rate $\sim 1000 \mathrm{~Gy} \mathrm{~h}^{-1}$ the expected rate of detectable pulses could approach $\sim 9 \times 10^{7} \mathrm{~s}^{-1}$, from a gamma fluence rate $\sim 10 \times 10^{14} \mathrm{~cm}^{-2} \mathrm{~s}^{-1}$. This might necessitate increasing the lower limit of detection in order to achieve adequate gamma rejection, with a corresponding reduction in neutron detection efficiency.

\section{COMPARISON OF GEANT4 AND MCNP SIMULATION RESULTS}

A preliminary comparison has been made between simulation results achieved with MCNP and those from Geant4. A Geant 4 model of the detector was implemented, and a simulation conducted using Geant4 10.05.01. The standard FTFP_BERT_HP physics list was used; of its features, the significant one for this application is the use of high-precision (data-driven) models and cross-sections for low-energy neutrons (including elastic scattering and neutron capture). In addition, step limiting physics was used, with a $0.1 \mu \mathrm{m}$ step

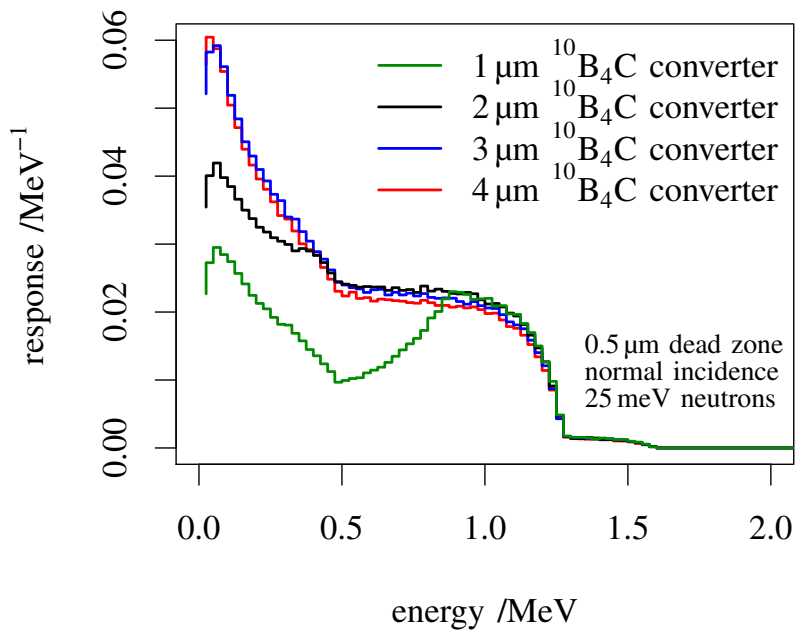

Fig. 4: Neutron response with a $0.5 \mu \mathrm{m}$ dead zone

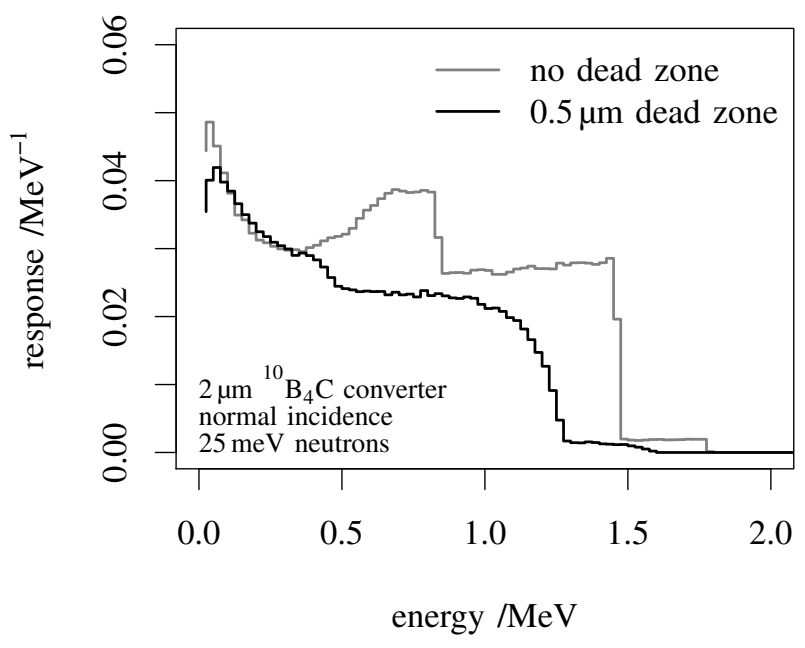

(a) Pulse-height spectrum

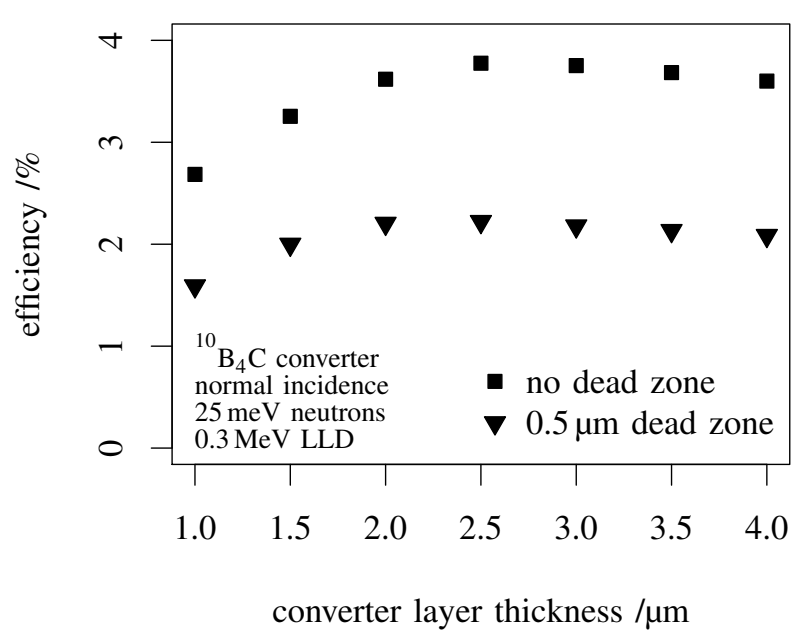

(b) Intrinsic efficiency, $0.3 \mathrm{MeV}$ lower limit of detection

Fig. 5: Neutron response with and without a dead zone 


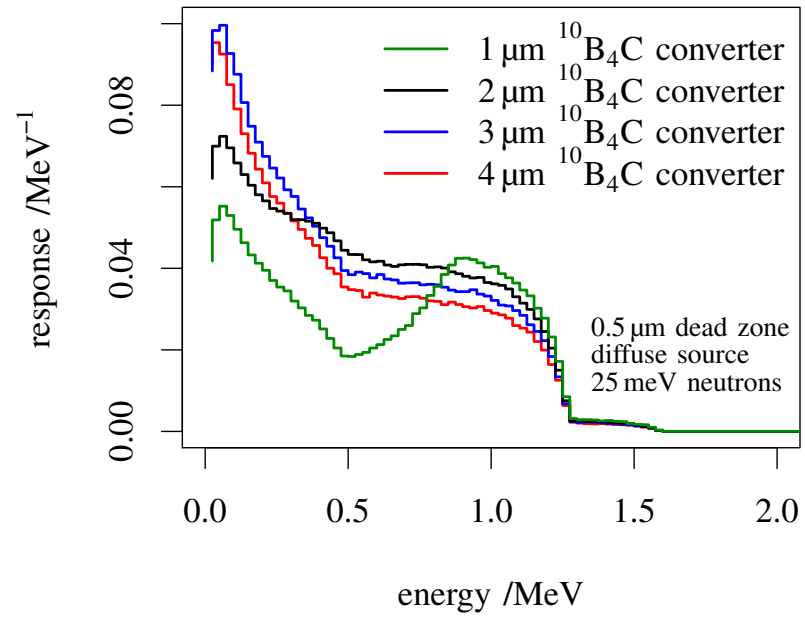

(a) Pulse-height spectrum

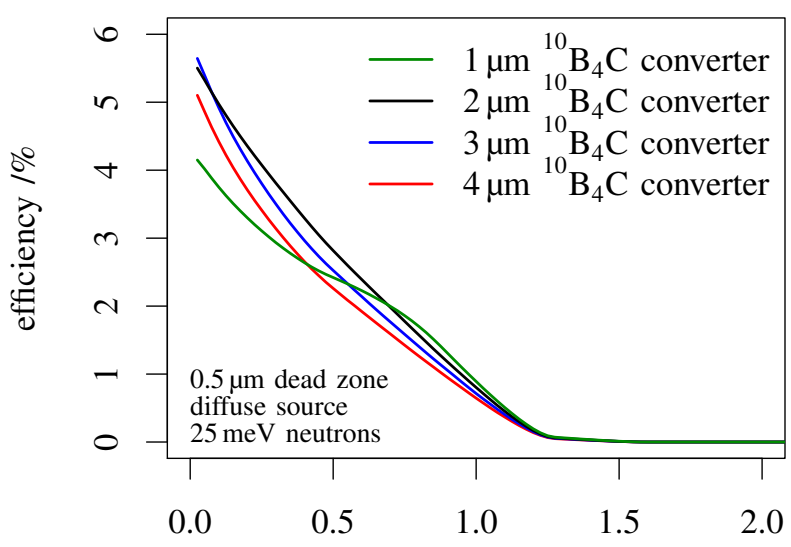

lower limit of detection $/ \mathrm{MeV}$

(b) Intrinsic efficiency

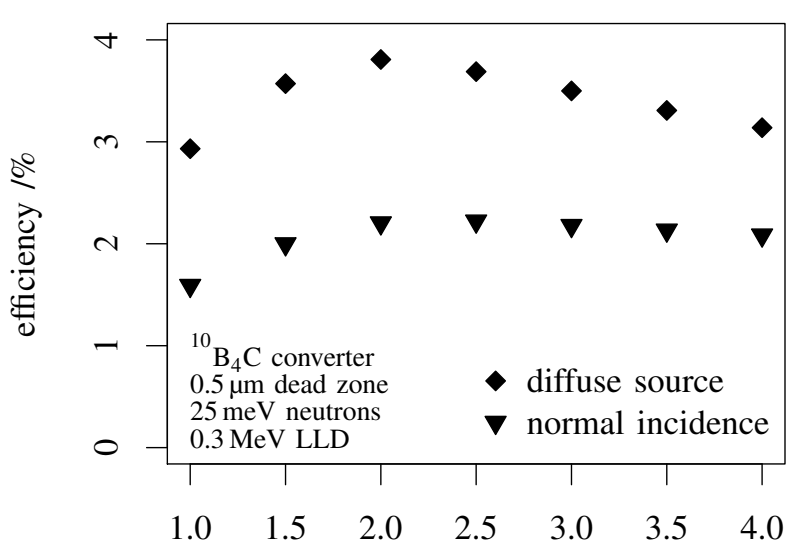

converter layer thickness $/ \mu \mathrm{m}$

(c) Intrinsic efficiency, $0.3 \mathrm{MeV}$ lower limit of detection

Fig. 6: Detector response to a diffuse neutron source

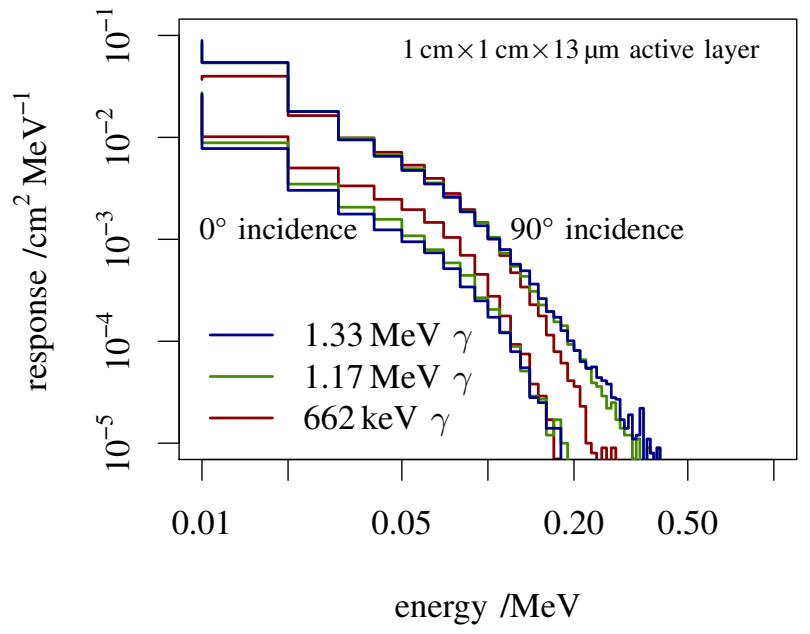

Fig. 7: Response to photons incident at $0^{\circ}$ and $90^{\circ}$ to normal

limit. Primary particles were monoenergetic $25 \mathrm{meV}$ neutrons and $1.33 \mathrm{MeV}$ photons, at normal incidence.

Fig. 8 compares Geant 4 and MCNP results for the case of a $1 \mathrm{~cm} \times 1 \mathrm{~cm}$ detector with $0.5 \mu \mathrm{m}$ dead zone and a $3 \mu \mathrm{m}$ ${ }^{10} \mathrm{~B}_{4} \mathrm{C}$ converter layer with $98 \%{ }^{10} \mathrm{~B}$ enrichment. Results are qualitatively similar, but the Geant 4 neutron response is $\sim 25 \%$ below the MCNP results over most of the energy range. Reasons for this discrepancy are being investigated. Results appear not to be sensitive to the choice of electromagnetic model in Geant4; those shown in Fig. 8 were generated using default electromagnetic physics.

\section{CONCLUSION}

Decommissioning the Fukushima Daiichi nuclear power plant has identified a requirement for a thin neutron detector system with good gamma rejection. MCNP simulations show that a silicon carbide PN diode with a ${ }^{10} \mathrm{~B}$-enriched boron carbide converter layer can achieve an intrinsic efficiency for thermal neutron detection approaching $4 \%$, assuming a detection threshold compatible with thermal noise from a largearea detector with capacitance $\sim 1 \mathrm{nF}$. Gamma discrimination, expressed in terms of the ratio of the response to $25 \mathrm{meV}$ neutrons to that to $662 \mathrm{keV}$ photons, is predicted to be of the order of $10^{5}: 1$.

At the time of presentation, a prototype ${ }^{10} \mathrm{~B}_{4} \mathrm{C}: \mathrm{SiC}$ detector is in fabrication.

\section{ACKNOWLEDGMENT}

We thank Prof. Tsuyoushi Misawa of Kyoto University for his support and collaboration.

\section{REFERENCES}

[1] T. Kimoto and J. A. Cooper, Fundamentals of Silicon Carbide Technology. Wiley-IEEE Press, 2014.

[2] A. A. Lebedev, Radiation Effects in Silicon Carbide. Materials Research Forum LLC, 2017.

[3] S. S. Suvanam, "Radiation hardness of $4 \mathrm{H}-\mathrm{SiC}$ devices and circuits," Ph.D. dissertation, KTH Royal Institute of Technology, 2017. 


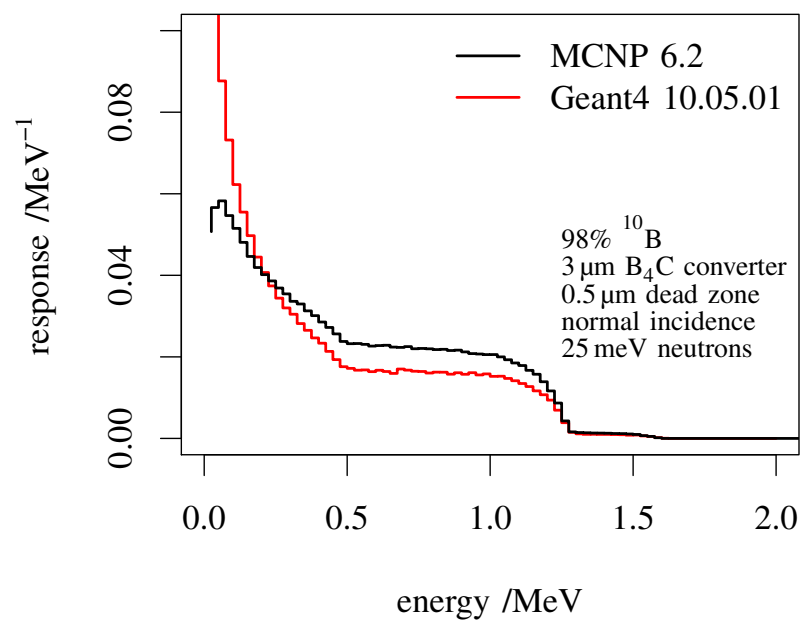

(a) Neutron pulse-height spectrum

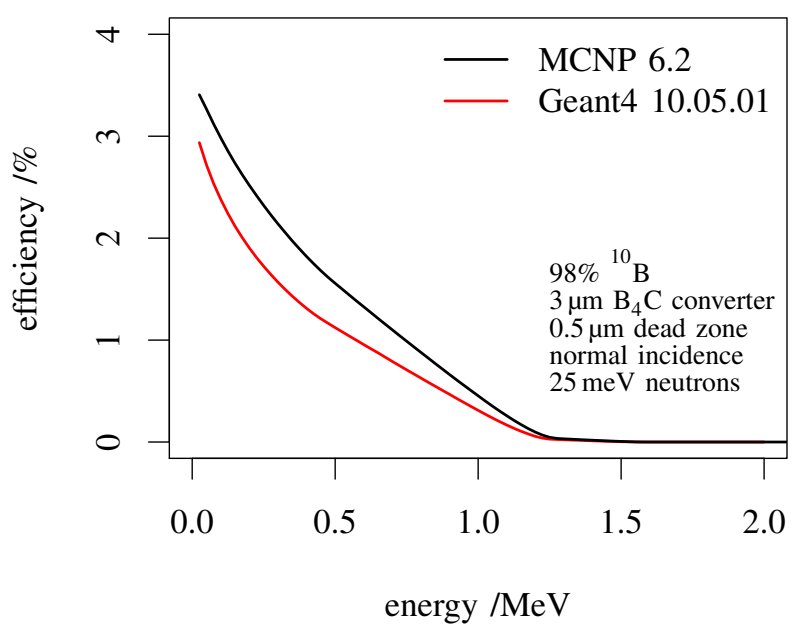

(b) Intrinsic neutron detection efficiency

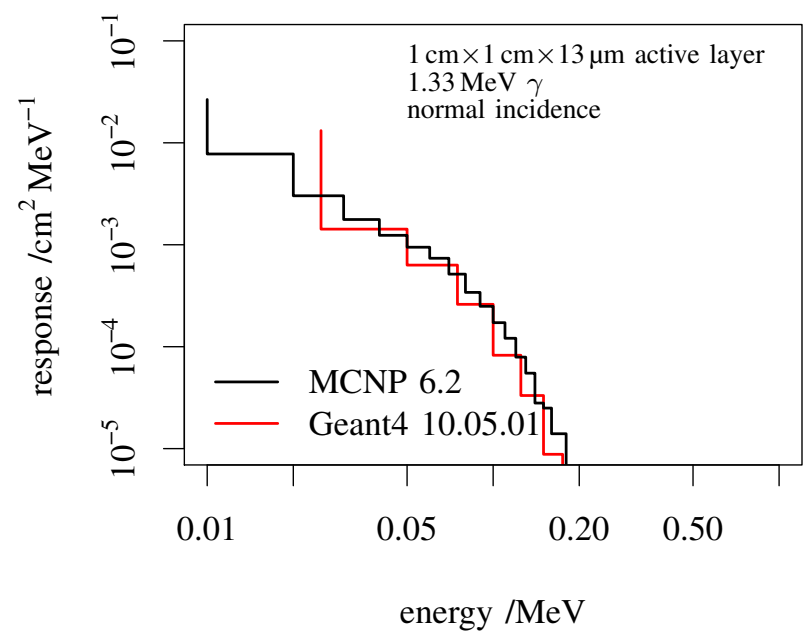

(c) Photon response

Fig. 8: MCNP and Geant4 simulation results compared
[4] R. V. Babcock and H. C. Chang, "SiC neutron detectors for hightemperature operation," in Neutron Dosim.: Proc. Symp. Neutron Detection, Dosimetry and Standardization Vol. 1. International Atomic Energy Agency, 1963, pp. 613-622.

[5] C. Manfredotti et al., "SiC detectors for neutron monitoring," Nucl. Instrum. Methods Phys. Res. A, vol. 552, pp. 131-137, Oct. 2005.

[6] F. Nava et al., "Silicon carbide and its use as a radiation detector material," Meas. Sci. Technol., vol. 19, p. 102001, Aug. 2008.

[7] B. D. Milbrath et al., "Radiation detector materials: An overview," $J$. Mater. Res., vol. 23, pp. 2561-2581, Oct. 2008.

[8] J. H. Ha et al., "4H-SiC PIN-type semiconductor detector for fast neutron detection," Prog. Nucl. Sci. Technol., vol. 1, pp. 237-239, 2011.

[9] M. Hodgson, "Silicon carbide and diamond neutron detectors for active interrogation security applications," Ph.D. dissertation, University of Surrey, 2015.

[10] Y. M. Abubakar, "Silicon and silicon carbide radiation detectors for alpha and neutron detection at elevated temperatures," Ph.D. dissertation, University of Surrey, Dec. 2016.

[11] M. Hodgson et al., "Characterization of silicon carbide and diamond detectors for neutron applications," Meas. Sci. Technol., vol. 28, p. 105501, Sep. 2017.

[12] K. Sedlačková et al., "Comparison of semi-insulating GaAs and 4H-SiCbased semiconductor detectors covered by $\mathrm{LiF}$ film for thermal neutron detection," Appl. Surf. Sci., vol. 461, pp. 242-248, Dec. 2018.

[13] S. Zhao et al., "X-ray spectrometer with a low-cost SiC photodiode," Nucl. Instrum. Methods Phys. Res. A, vol. 887, pp. 138-143, Apr. 2018.

[14] S. Zhao et al., "Electron spectroscopy with a commercial 4H-SiC photodiode," Nucl. Instrum. Methods Phys. Res. A, vol. 910, pp. 35-40, Dec. 2018.

[15] Y. Jiang et al., "A neutron beam monitor based on silicon carbide semiconductor coated with $6 \mathrm{LiF}$ converter," Nucl. Instrum. Methods Phys. Res. A, vol. 921, pp. 14-17, Mar. 2019.

[16] R. Hedayati, "High-temperature analog and mixed-signal integrated circuits in bipolar silicon carbide technology," Ph.D. dissertation, KTH Royal Institute of Technology, 2017.

[17] M. Ekström, "SiC CMOS and memory devices for high-temperature integrated circuits," Ph.D. dissertation, KTH Royal Institute of Technology, 2019.

[18] “MCNP ${ }^{\circledR}$ User’s Manual Code Version 6.2," Los Alamos National Laboratory, Technical Report LA-UR-17-29981, 2017. [Online]. Available: https://monp.lanl.gov/pdf_files/la-ur-17-29981.pdf

[19] Geant4: A simulation toolkit. Web site. [Online]. Available: http://geant4. web.cern.ch

[20] S. Agostinelli et al., "Geant4-a simulation toolkit," Nucl. Instrum. Methods Phys. Res. A, vol. 506, pp. 250-303, Jul. 2003.

[21] J. Allison et al., "Geant4 developments and applications," IEEE Trans. Nucl. Sci., vol. 53, pp. 270-278, Feb. 2006.

[22] J. Allison et al., "Recent developments in Geant4," Nucl. Instrum. Methods Phys. Res. A, vol. 835, pp. 186-225, Nov. 2016.

[23] D. A. Brown et al., "ENDF/B-VIII.0: The $8^{\text {th }}$ major release of the nuclear reaction data library with CIELO-project cross sections, new standards and thermal scattering data," Nucl. Data Sheets, vol. 148, pp. 1-142, Feb. 2018.

[24] National Nuclear Data Center. Web site. [Online]. Available: https: //www.nndc.bnl.gov/

[25] D. S. McGregor et al., "Design considerations for thin film coated semiconductor thermal neutron detectors - I: basics regarding alpha particle emitting neutron reactive films," Nucl. Instrum. Methods Phys. Res. A, vol. 500, pp. 272-308, Mar. 2003.

[26] A. N. Caruso, "The physics of solid-state neutron detector materials and geometries," J. Phys. Cond. Matter, vol. 22, p. 443201, Oct. 2010.

[27] C. Höglund et al., " $\mathrm{B}_{4} \mathrm{C}$ thin films for neutron detection," J. App. Phys., vol. 111, p. 104908, May 2012.

[28] F. Piscitelli, "Boron-10 layers, neutron reflectometry and thermal neutron gaseous detectors," Ph.D. dissertation, Università degli Studi di Perugia, 2014.

[29] G. Nowak et al., "Boron carbide coatings for neutron detection probed by x-rays, ions, and neutrons to determine thin film quality," J. App. Phys., vol. 117, p. 034901, Jan. 2015.

[30] G. Celentano et al., " ${ }^{10} \mathrm{~B}$ enriched film deposited by e-beam technique on $\mathrm{Al}_{2} \mathrm{O}_{3}$ substrate for high efficiency thermal neutron detector," Surface and Coatings Technology, vol. 265, pp. 160-165, Mar. 2015.

[31] A. Pappalardo et al., "Characterization of the silicon+6LiF thermal neutron detection technique," Nucl. Instrum. Methods Phys. Res. A, vol. 810 , pp. 6-13, Feb. 2016 
[32] G. Croci et al., "A high-efficiency thermal neutron detector based on thin $3 \mathrm{D}{ }^{10} \mathrm{~B}_{4} \mathrm{C}$ converters for high-rate applications," Europhys. Lett., vol. 123, p. 52001, Oct. 2018.

[33] P. Kandlakunta et al., "Measurement of internal conversion electrons from Gd neutron capture," Nucl. Instrum. Methods Phys. Res. A, vol. 705, pp. 36-41, Mar. 2013.

[34] P. Kandlakunta and L. R. Cao, "Neutron conversion efficiency and gamma interference with gadolinium," J. Radioanalyt. Nucl. Chem., vol. 300, pp. 953-961, Mar. 2014.
[35] K. B. Pfeifer et al., "Microfabrication of a gadolinium-derived solid-state sensor for thermal neutrons," J. Radiat. Res., vol. 58, pp. 464-473, Mar. 2017.

[36] J. Dumazert et al., "Gadolinium for neutron detection in current nuclear instrumentation research: A review," Nucl. Instrum. Methods Phys. Res. A, vol. 882, pp. 53-68, Feb. 2018.

[37] M. M. Ninkovic et al., "Air kerma rate constants for gamma emitters used most often in practice," Radiat. Prot. Dosim., vol. 115, pp. 247250, Dec. 2005. 